\title{
Topical amiodarone: To be or not to be effective?
}

\author{
Jun Feng, MD, PhD
}

\footnotetext{
From the Division of Cardiothoracic Surgery, Cardiovascular Research Center, Rhode Island Hospital, Alpert Medical School of Brown University, Providence, RI.

Disclosures: Author has nothing to disclose with regard to commercial support.

Received for publication April 13, 2017; accepted for publication April 13, 2017; available ahead of print May 11, 2017.

Address for reprints: Jun Feng, MD, PhD, Division of Cardiothoracic Surgery, Cardiovascular Research Center, Rhode Island Hospital, Coro West, Room 5.229, 1 Hoppin St, Providence, RI 02903 (E-mail: jfeng@ lifesapn. org).

J Thorac Cardiovasc Surg 2017;154:893-4

$0022-5223 / \$ 36.00$

Copyright (C) 2017 by The American Association for Thoracic Surgery

http://dx.doi.org/10.1016/j.jtcvs.2017.04.028
}

Treatment of postoperative atrial fibrillation is still a big challenge for cardiac surgeons. In their observational study in this issue of the Journal, Greenstein and colleagues ${ }^{1}$ evaluated the therapeutic effects of the epicardial application of amiodarone for the prevention of postoperative atrial fibrillation. Contrary to previous studies of Feng and Wang group, ${ }^{2,3}$ Greenstein and colleagues ${ }^{1}$ in this study presented new findings regarding their inability to reproduce previously reported results of the topical application of amiodarone in the prevention of postoperative atrial fibrillation. This is an interesting and important retrospective study in a single hospital. Greenstein and colleagues ${ }^{1}$ are the first to use an amiodarone-soaked sealant patch to assess its efficacy in the prevention of postoperative atrial fibrillation. Greenstein and colleagues ${ }^{1}$ are to be congratulated on their elegant study, even if they generated controversial, negative results. Their study will encourage and drive more scientific debates, inspire future studies, and stimulate innovation in the perioperative management of atrial fibrillation. The peer reviewers and editors of this Journal carefully reviewed and rereviewed this article, and they raised a number of important issues concerning the newly negative findings from this excellent group. The issues and comments raised by the reviewers and editors were mainly focused on surgical techniques for epicardial application of topical amiodarone and power estimation of data analysis. Greenstein and colleagues ${ }^{1}$ therefore devoted much of their Discussion section to explaining the discrepancies between their study and those of the Feng and Wang group. ${ }^{2,3}$

Obviously, it is difficult to explain the contradictory results between these negative findings and the positive reports of previous studies. ${ }^{2,3}$ Several limitations of the current study, however, should be specifically emphasized. From the surgical technique point of view, Greenstein and colleagues ${ }^{1}$ did not routinely dissect under the superior vena cava, as described by Feng and Wang group. ${ }^{2,3}$ In addition, Greenstein and colleagues ${ }^{1}$ did not measure the blood or tissue sample concentration of amiodarone to verify the efficacy of local drug delivery, even

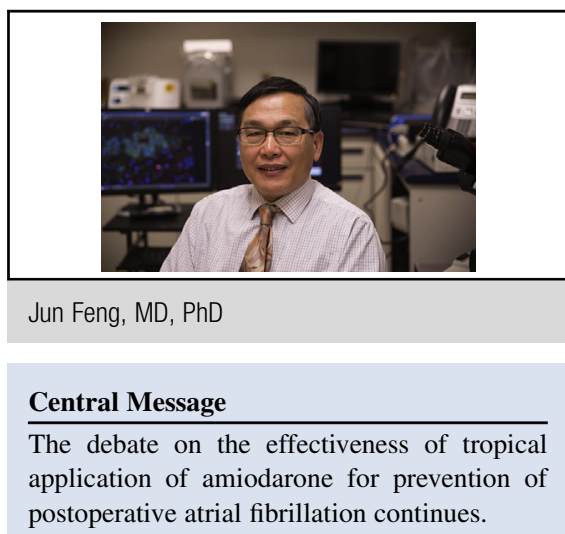

See Article page 886.

though the Feng and Wang group ${ }^{2,3}$ had previously performed this procedure in their studies. Furthermore, a relatively high dose of amiodarone was used in the study of Greenstein and colleagues ${ }^{1}$; however, a higher dose might have caused toxicity instead of therapy. This issue has been previously commented on by Beau and Kulik ${ }^{4}$ and by Wang ${ }^{5}$ in the Journal. Dose-dependent effects of amiodarone should be therefore be examined in future studies for further examination of its efficacy. Meanwhile, further experimental investigation into the efficacies of different hydrogels and patches on the release and delivery of amiodarone is also imperative.

From a statistical point of view, the study of Greenstein and colleagues ${ }^{1}$ and 2 previous studies ${ }^{2,3}$ are considered as pilot studies and were performed within a single center. Even though these authors provided a power estimation in the data analysis, interpretation of current negative findings and those positive reports should still receive a word of caution because of the characteristics, including relatively small size, of the cohorts. Many factors or characteristics of the enrolled cases may have affected the current negative findings and the positive results of previous studies, such as age, sex, obesity, diabetes, hypertension, myocardial infarction, smoking, cardiopulmonary bypass time, crossclamp time, and preoperative and postoperative medications. To avoid the influences of these multiple factors, it is recommended that an additional hundred cases should be added to each group in future clinical trials. Moreover, double-blind, randomized, multicenter studies are also required in the near future for further examination of the potential therapeutic effects of epicardial application of topical amiodarone for prevention of postoperative atrial fibrillation. 


\section{References}

1. Greenstein D, Beau J, Gottlieb G, Teller D, Kulik A. Topical amiodarone during cardiac surgery: does epicardial application of amiodarone prevent postoperative atrial fibrillation? J Thorac Cardiovasc Surg. 2017;154:886-92.

2. Feng DX, Wang XN, Yuan XH, Wang W. Effectiveness of biatrial epicardial application of amiodarone-releasing adhesive hydrogel to prevent postoperative atrial fibrillation. J Thorac Cardiovasc Surg. 2014;148:939-43.
3. Wang W, Mei YQ, Yuan XH, Feng XD. Clinical efficacy of epicardial application of drug-releasing hydrogels to prevent postoperative atrial fibrillation. $J$ Thorac Cardiovasc Surg. 2016;151:80-5.

4. Beau J, Kulik A. Topical amiodarone to prevent postoperative atrial fibrillation: need for further study. J Thorac Cardiovasc Surg. 2016;151:600.

5. Wang W. Considerations for the success of topical amiodarone to prevent postoperative atrial fibrillation. J Thorac Cardiovasc Surg. 2016;151:600-1. 